JAMA | Original Investigation

\title{
Effect of Depth and Duration of Cooling on Death or Disability at Age 18 Months Among Neonates With Hypoxic-Ischemic Encephalopathy A Randomized Clinical Trial
}

\begin{abstract}
Seetha Shankaran, MD; Abbot R. Laptook, MD; Athina Pappas, MD; Scott. A. McDonald, BS; Abhik Das, PhD; Jon E. Tyson, MD, MPH; Brenda B. Poindexter, MD, MS; Kurt Schibler, MD; Edward F. Bell, MD; Roy J. Heyne, MD; Claudia Pedroza, PhD; Rebecca Bara, RN, BSN; Krisa P. Van Meurs, MD; Carolyn M. Petrie Huitema, MS, CCRP; Cathy Grisby, BSN, CCRC; Uday Devaskar, MD; Richard A. Ehrenkranz, MD; Heidi M. Harmon, MD, MS; Lina F. Chalak, MD, MSCS; Sara B. DeMauro, MD, MSCE; Meena Garg, MD; Michelle E. Hartley-McAndrew, MD; Amir M. Khan, MD; Michele C. Walsh, MD, MS; Namasivayam Ambalavanan, MD; Jane E. Brumbaugh, MD; Kristi L. Watterberg, MD; Edward G. Shepherd, MD; Shannon E. G. Hamrick, MD; John Barks, MD; C. Michael Cotten, MD, MHS; Howard W. Kilbride, MD; Rosemary D. Higgins, MD; for the Eunice Kennedy Shriver National Institute of Child Health and Human Development Neonatal Research Network
\end{abstract}

IMPORTANCE Hypothermia for 72 hours at $33.5^{\circ} \mathrm{C}$ for neonatal hypoxic-ischemic encephalopathy reduces death or disability, but rates continue to be high.

OBJECTIVE To determine if cooling for 120 hours or to a temperature of $32.0^{\circ} \mathrm{C}$ reduces death or disability at age 18 months in infants with hypoxic-ischemic encephalopathy.

DESIGN, SETTING, AND PARTICIPANTS Randomized $2 \times 2$ factorial clinical trial in neonates ( $\geq 36$ weeks' gestation) with hypoxic-ischemic encephalopathy at 18 US centers in the Eunice Kennedy Shriver National Institute of Child Health and Human Development Neonatal Research Network between October 2010 and January 2016.

INTERVENTIONS A total of 364 neonates were randomly assigned to 4 hypothermia groups: $33.5^{\circ} \mathrm{C}$ for 72 hours $(n=95), 32.0^{\circ} \mathrm{C}$ for 72 hours $(n=90), 33.5^{\circ} \mathrm{C}$ for 120 hours $(n=96)$, or $32.0^{\circ} \mathrm{C}$ for 120 hours $(n=83)$.

MAIN OUTCOMES AND MEASURES The primary outcome was death or moderate or severe disability at 18 to 22 months of age adjusted for center and level of encephalopathy. Severe disability included any of Bayley Scales of Infant Development III cognitive score less than 70, Gross Motor Function Classification System (GMFCS) level of 3 to 5, or blindness or hearing loss despite amplification. Moderate disability was defined as a cognitive score of 70 to 84 and either GMFCS level 2, active seizures, or hearing with amplification.

RESULTS The trial was stopped for safety and futility in November 2013 after 364 of the planned 726 infants were enrolled. Among 347 infants (95\%) with primary outcome data (mean age at follow-up, 20.7 [SD, 3.5] months; 42\% female), death or disability occurred in 56 of 176 (31.8\%) cooled for 72 hours and 54 of 171 (31.6\%) cooled for 120 hours (adjusted risk ratio, 0.92 [95\% Cl, 0.68-1.25]; adjusted absolute risk difference, $-1.0 \%[95 \% \mathrm{Cl},-10.2 \%$ to $8.1 \%]$ ) and in 59 of $185(31.9 \%)$ cooled to $33.5^{\circ} \mathrm{C}$ and 51 of $162(31.5 \%)$ cooled to $32.0^{\circ} \mathrm{C}$ (adjusted risk ratio, 0.92 [95\% Cl, 0.68-1.26]; adjusted absolute risk difference, $-3.1 \%$ [95\% $\mathrm{Cl},-12.3 \%$ to $6.1 \%]$ ). A significant interaction between longer and deeper cooling was observed $(P=.048)$, with primary outcome rates of $29.3 \%$ at $33.5^{\circ} \mathrm{C}$ for 72 hours, $34.5 \%$ at $32.0^{\circ} \mathrm{C}$ for 72 hours, $34.4 \%$ at $33.5^{\circ} \mathrm{C}$ for 120 hours, and $28.2 \%$ at $32.0^{\circ} \mathrm{C}$ for 120 hours.

CONCLUSIONS AND RELEVANCE Among term neonates with moderate or severe hypoxic-ischemic encephalopathy, cooling for longer than 72 hours, cooling to lower than $33.5^{\circ} \mathrm{C}$, or both did not reduce death or moderate or severe disability at 18 months of age. However, the trial may be underpowered, and an interaction was found between longer and deeper cooling. These results support the current regimen of cooling for 72 hours at $33.5^{\circ} \mathrm{C}$.

TRIAL REGISTRATION clinicaltrials.gov Identifier: NCT01192776

JAMA. 2017;318(1):57-67. doi:10.1001/jama.2017.7218
Supplemental content

Author Affiliations: Author affiliations are listed at the end of this article.

Group Information: The Eunice Kennedy Shriver National Institute of Child Health and Human

Development Neonatal Research Network members are listed at the end of this article.

Corresponding Author: Seetha Shankaran, MD, Children's Hospital of Michigan, 3901 Beaubien Blvd, Detroit, MI 48201 (sshankar@med .wayne.edu). 
$\mathrm{H}$ ypothermia at $33.5^{\circ} \mathrm{C}$ for 72 hours initiated within 6 hours of birth among neonates born at full term with evidence of moderate or severe hypoxic-ischemic encephalopathy has reduced the rates of death or survival with disability in infancy ${ }^{1,2}$ and childhood. ${ }^{3,4}$ Data from animal studies published 10 years after the initial clinical neuroprotection trials ${ }^{1,2}$ demonstrated that cooling to a depth of $32.0^{\circ} \mathrm{C}$ or for a duration longer than 72 hours is neuroprotective. ${ }^{5,6}$ In an attempt to further decrease the rate of death or disability associated with hypoxic-ischemic encephalopathy, the current randomized clinical trial was designed to test whether longer cooling (120 hours), deeper cooling $\left(32.0^{\circ} \mathrm{C}\right)$, or both decreases death or disability at 18 months of age compared with cooling at $33.5^{\circ} \mathrm{C}$ for 72 hours. A previous report from this study included 4 secondary outcomes (neonatal intensive care unit [NICU] deaths, acute adverse events, multiorgan dysfunction, and NICU length of stay). ${ }^{7}$ This article reports the primary outcomes of death or disability (moderate or severe) at age 18 to 22 months.

\section{Methods}

The study was conducted at all 18 US sites in the Eunice Kennedy Shriver National Institute of Child Health and Human Development (NICHD) Multicenter Neonatal Research Network between October 2010 and January 2016, with RTI International as the data coordinating center. Criteria for eligibility and details of cooling and rewarming were similar to the first NICHD randomized clinical trial of therapeutic hypothermia ${ }^{1}$ and published previously. ${ }^{7}$ Random assignment was stratified by center and level of encephalopathy (moderate or severe) in a $2 \times 2$ factorial design to $33.5^{\circ} \mathrm{C}$ or $32.0^{\circ} \mathrm{C}$ and to 72 hours or 120 hours. Neonates who were born at 36 weeks' or greater gestation were enrolled. The trial protocol is available in Supplement 1 . An independent data and safety monitoring committee monitored interim data and evaluated safety.

The protocol was approved by the institutional review board at each site. Written informed consent was obtained from parents of study participants.

\section{Outcomes}

The primary outcome was death or moderate or severe disability at 18 to 22 months of age. This composite outcome was selected because death is a competing outcome for disability. Infants were evaluated at 18 to 22 months of age; the families of those who did not return for follow-up were contacted by telephone to obtain information about the primary outcome. Data on growth, vision, and hearing were obtained, and neurological and developmental testing was performed by trained examiners who were masked to intervention status.

Neuromotor disability was based on the presence of cerebral palsy, and functional disability was graded according to the Gross Motor Function Classification System (GMFCS, levels 1-5; level 1 includes children who walk but gait is not fluent; level 2 includes those who are unable to walk but who can pull to stand and take steps holding on to furniture; level 3 in-

\section{Key Points}

Question Is cooling for 120 hours, cooling to $32.0^{\circ} \mathrm{C}$, or both more neuroprotective than cooling for 72 hours at $33.5^{\circ} \mathrm{C}$, the current standard of care, among neonates with moderate or severe hypoxic-ischemic encephalopathy at birth?

Findings In this randomized clinical trial that included 364 neonates, there was no significant difference in the probability of death or disability at 18 months of age comparing cooling at 120 hours (31.6\%) vs 72 hours (31.8\%) or to a depth of $32.0^{\circ} \mathrm{C}(31.5 \%)$ vs $33.5^{\circ} \mathrm{C}(31.9 \%)$.

Meaning These findings do not support change from the current regimen of cooling for 72 hours at $33.5^{\circ} \mathrm{C}$ for neonates with moderate or severe encephalopathy; however, statistical interactions between duration and depth of cooling support the possibility of higher mortality with the combination of longer and deeper cooling, suggesting that further investigation may be warranted.

cludes those who use hands for sitting support and are unable to crawl, level 4 includes those for whom support is needed for sitting; and level 5 includes those who require adult assistance to move) ${ }^{8}$ Cognitive outcome was assessed by the Bayley Scales of Infant Development III (reported mean, 100 $[S D, 15]) .{ }^{9}$ Severe disability was defined as any of the following: a Bayley III cognitive score of less than 70, a GMFCS level of 3 to 5, blindness, or profound hearing loss (inability to understand commands despite amplification). Moderate disability was defined as a Bayley III cognitive score of 70 to 84 and either a GMFCS level of 2, seizure disorder, or a hearing deficit requiring amplification to understand commands. Mild disability was defined as a cognitive score of 70 to 84 , or a cognitive score of 85 or higher and any of the following: presence of a GMFCS level 1 or 2, seizure disorder, or hearing loss not requiring amplification. Normal neurocognitive status was defined as a cognitive score of 85 or higher in the absence of any neurosensory deficits or seizures after NICU discharge.

Prespecified secondary outcomes in this report include postNICU discharge mortality; level of disability by stage of encephalopathy; rates of vision, hearing, and multiple disabilities; cognitive and motor scores; cerebral palsy rates; rehospitalization rates; and growth measurements. Neonatal brain magnetic resonance imaging findings will be reported separately.

\section{Statistical Analysis}

A sample size of 726 neonates (363 in each group to compare the 2 durations of cooling and the 2 depths of cooling) was based on a 2-tailed $a=.05$, a statistical power of $80 \%$, a $5 \%$ loss to followup, and a comparison of death or disability of 37.5\% and $27.5 \%$ in the 2 durations and depth-of-cooling groups. Generalized estimating equation (GEE) models with log link were used to obtain relative risk (RR) estimates for binary outcomes, adjusting for level of encephalopathy and intracenter correlations. Continuous outcomes were similarly assessed using GEE linear regression after log transformation. Treatment interactions between the 2 factors (deeper and longer cooling) were assessed for the primary outcome and key secondary outcomes. All reported $P$ values are 2-sided and not adjusted for multiple comparisons. $P<.05$ was considered statistically significant. 


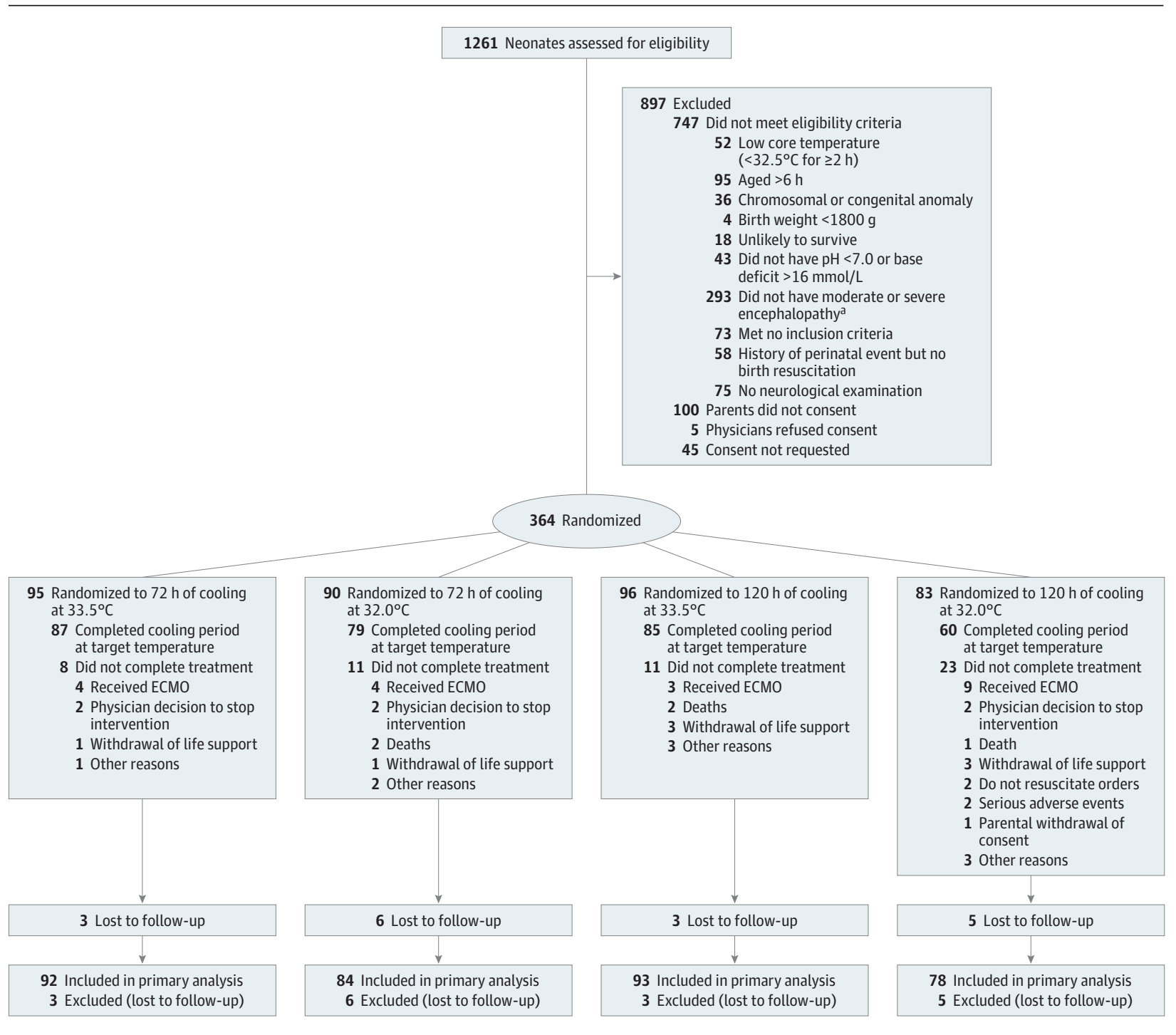

ECMO indicates extracorporeal membrane oxygenation.

${ }^{\text {a }}$ Moderate or severe encephalopathy was defined as the presence of 1 or more signs in at least 3 of the following 6 categories: (1) level of consciousness (moderate is lethargic, severe is stupor or coma); (2) spontaneous activity (moderate is decreased activity, severe is no activity); (3) posture (moderate is distal flexion or complete extension, severe is decerebrate); (4) tone

(moderate is hypotonia, severe is flaccid); (5) primitive reflexes (moderate is a weak suck, severe is an absent suck, or moderate is incomplete Moro reflex and severe is absent); and (6) autonomic nervous system-either pupil (moderate is constricted; severe is deviated, dilated, or nonreactive to light), heart rate (moderate is bradycardia, severe is variable heart rate), or respiration (moderate is periodic breathing, severe is apnea).
To obtain probability estimates of treatment effect for the 3 experimental groups, a Bayesian analysis of death or disability or death alone was conducted. A log binomial model with level of encephalopathy and main effects of cooling duration and depth and their interaction was used to estimate posterior median of the RRs and 95\% credible intervals (CrIs). The model also included a random center effect and used neutral priors for treatment effects centered at an RR of 1 (95\% prior interval, 0.5-2.0). ${ }^{10}$ Weakly informative priors were used for all other parameters to exclude large treatment effects and produce conservative estimates of treatment effects (see eAppendix in Supplement 2 for details). The statistical software used was SAS, version 9.3 (SAS Institute Inc).

\section{Results}

The trial was closed for in-hospital mortality and futility concerns by the data safety and monitoring committee after 1261 neonates had been screened, 514 were eligible, and 364 were enrolled (Figure). ${ }^{7}$ At 18 to 22 months of age, the primary outcome was available for 176 infants in the 72-hour group, 171 in the 120 -hour group, 185 in the $33.5^{\circ} \mathrm{C}$ group, and 162 in the $32.0^{\circ} \mathrm{C}$ group. The baseline maternal and neonatal characteristics of the 72 -hour and 120 -hour groups and the $33.5^{\circ} \mathrm{C}$ and $32.0^{\circ} \mathrm{C}$ groups are shown in Table 1 and those across all 4 randomization groups are presented in the eTable in Supplement 


\begin{tabular}{|c|c|c|c|c|}
\hline \multirow[b]{2}{*}{ Characteristics } & \multicolumn{2}{|l|}{ Duration of Cooling } & \multicolumn{2}{|l|}{ Depth of Cooling } \\
\hline & $\begin{array}{l}72 \mathrm{~h} \\
(\mathrm{n}=176)\end{array}$ & $\begin{array}{l}120 \mathrm{~h} \\
(\mathrm{n}=171)\end{array}$ & $\begin{array}{l}33.5^{\circ} \mathrm{C} \\
(\mathrm{n}=185)\end{array}$ & $\begin{array}{l}32.0^{\circ} \mathrm{C} \\
(\mathrm{n}=162)\end{array}$ \\
\hline \multicolumn{5}{|l|}{ Maternal characteristics } \\
\hline \multicolumn{5}{|l|}{ Race, No. (\%) } \\
\hline Black & $51(29)$ & $56(33)$ & $58(32)$ & $49(31)$ \\
\hline White & $113(65)$ & $98(58)$ & $112(61)$ & $99(62)$ \\
\hline Other $^{\mathrm{b}}$ & $11(6)$ & $14(8)$ & $13(7)$ & $12(8)$ \\
\hline Age, mean (SD), y & $28.1(6.6)$ & $28.1(7.0)$ & $28.3(6.6)$ & $27.9(7.0)$ \\
\hline Married, No. (\%) & $93(53)$ & $89(52)$ & $100(55)$ & $82(51)$ \\
\hline Gravida, median (IQR) & $2(1-3)$ & $2(1-3)$ & $2(1-3)$ & $2(1-3)$ \\
\hline Parity, median (IQR) & $1(1-3)$ & $1(1-3)$ & $1(1-3)$ & $1(1-2)$ \\
\hline \multicolumn{5}{|l|}{ Pregnancy complications, No. (\%) } \\
\hline Chronic hypertension & $37(21)$ & $33(20)$ & $33(18)$ & $37(23)$ \\
\hline Antepartum hemorrhage & $22(13)$ & $16(9)$ & $20(11)$ & $18(11)$ \\
\hline Thyroid dysfunction & $11(6)$ & $3(2)$ & $6(3)$ & $8(5)$ \\
\hline Diabetes & $21(12)$ & $24(14)$ & $22(12)$ & $23(14)$ \\
\hline \multicolumn{5}{|l|}{ Intrapartum complications, №. (\%) } \\
\hline Decelerations in fetal heart rate & $134(77)$ & $134(79)$ & $144(79)$ & $124(77)$ \\
\hline Cord prolapse, rupture, or compression & $26(15)$ & $20(12)$ & $28(15)$ & $18(11)$ \\
\hline Uterine rupture & $11(6)$ & $11(6)$ & $9(5)$ & $13(8)$ \\
\hline Maternal pyrexia $\left(\geq 37.6^{\circ} \mathrm{C}\right)$ & $23(13)$ & $18(11)$ & $17(9)$ & $24(15)$ \\
\hline Shoulder dystocia & $14(8)$ & $14(8)$ & $14(8)$ & $14(9)$ \\
\hline Maternal hemorrhage & $25(14)$ & $28(16)$ & $29(16)$ & $24(15)$ \\
\hline \multicolumn{5}{|c|}{$\begin{array}{l}\text { Rupture of membranes (spontaneous or induced), } \\
\text { No. (\%) }\end{array}$} \\
\hline None & $44(26)$ & $49(30)$ & $55(31)$ & $38(25)$ \\
\hline$\leq 18 \mathrm{~h}$ prior to delivery & $111(65)$ & $94(58)$ & $108(60)$ & $97(63)$ \\
\hline$>18 \mathrm{~h}$ prior to delivery & $16(9)$ & $20(12)$ & $17(9)$ & $19(12)$ \\
\hline \multicolumn{5}{|l|}{ Rupture of membranes, $\mathrm{h}$ prior to delivery } \\
\hline Mean (SD) & $11.1(19.6)$ & $10.8(16.8)$ & $10.9(16.5)$ & $11.0(20.0)$ \\
\hline Median (IQR) & $7.6(2.7-14.7)$ & $5.9(2.1-14.3)$ & $6.4(2.3-14.1)$ & $7.3(1.8-15.1)$ \\
\hline Emergency cesarean delivery, №. (\%) & $111(63)$ & $107(63)$ & $113(61)$ & $105(65)$ \\
\hline
\end{tabular}

2. The primary outcome of death or moderate or severe disability occurred in 56 of 176 infants (31.8\%) in the 72-hour group, 54 of 171 infants (31.6\%) in the 120-hour group, 59 of 185 infants $(31.9 \%)$ in the $33.5^{\circ} \mathrm{C}$ group, and 51 of 162 infants (31.5\%) in the $32.0^{\circ} \mathrm{C}$ group (Table 2 ). The adjusted RRs for the primary outcome for duration or depth of cooling were not significantly different. The primary outcome was similar among infants with moderate or severe encephalopathy between the 120 -hour and 72-hour groups and between the $32.0^{\circ} \mathrm{C}$ and $33.5^{\circ} \mathrm{C}$ groups.

Most of the secondary outcomes did not differ by duration or depth of cooling, with the exception of more deaths but fewer rehospitalizations after discharge and infants with motor scores less than 70 with duration of cooling of 120 hours vs 72 hours (Table 2). Very few surviving infants had moderate disability. An interaction test between depth and duration of cooling in this $2 \times 2$ factorial design trial was statistically significant for the primary outcome $(P=.048)$. Rates of the primary outcomes in the 4 groups were $29.3 \%$ (27 of 92 in- fants) in the group with $33.5^{\circ} \mathrm{C}$ for 72 hours, $34.5 \%$ (29 of 84 infants) in the group with $32.0^{\circ} \mathrm{C}$ for 72 hours, $34.4 \%$ (32 of 93 infants) in the group with $33.5^{\circ} \mathrm{C}$ for 120 hours, and $28.2 \%$ (22 of 78 infants) in the group with $32.0^{\circ} \mathrm{C}$ for 120 hours (Table 3 ). The Bayesian analyses of the posterior probabilities of reducing death or moderate or severe disability with deeper cooling, longer cooling, or both compared with standard cooling (probability of $\mathrm{RR}<1.0$ ) were $58 \%, 50 \%$, and $78 \%$, respectively. There was no statistically significant interaction for death ( $P=.11$ ) or any other secondary outcome other than a Bayley III cognitive score of 70 to 84 vs 85 or higher $(P=.049)$ and a Bayley III motor score of less than 70 vs 85 or higher $(P=.04)$.

The mortality rates in the 4 hypothermia groups are noted in the eFigure in Supplement 2. The adjusted RR for death was higher in the group with $33.5^{\circ} \mathrm{C}$ for 120 hours vs the group with $33.5^{\circ} \mathrm{C}$ for 72 hours (RR, 2.52; 95\% CI, 1.06-5.95) (Table 3). The Bayesian estimates of the adjusted RRs for mortality for the 3 intervention groups compared with standard cooling were 1.08 (95\% CrI, 0.74-1.59) for the group with $32.0^{\circ} \mathrm{C}$ for 72 hours, 1.33 


\begin{tabular}{|c|c|c|c|c|}
\hline \multirow[b]{2}{*}{ Characteristics } & \multicolumn{2}{|l|}{ Duration of Cooling } & \multicolumn{2}{|c|}{ Depth of Cooling } \\
\hline & $\begin{array}{l}72 \mathrm{~h} \\
(\mathrm{n}=176)\end{array}$ & $\begin{array}{l}120 \mathrm{~h} \\
(\mathrm{n}=171)\end{array}$ & $\begin{array}{l}33.5^{\circ} \mathrm{C} \\
(\mathrm{n}=185)\end{array}$ & $\begin{array}{l}32.0^{\circ} \mathrm{C} \\
(\mathrm{n}=162)\end{array}$ \\
\hline \multicolumn{5}{|l|}{ Neonatal characteristics } \\
\hline Age at randomization, mean (SD), h & $5.0(1.1)$ & $4.9(1.4)$ & $4.9(1.1)$ & $4.9(1.4)$ \\
\hline Transferred from birth hospital, No. (\%) & $114(65)$ & $111(65)$ & $121(65)$ & $104(64)$ \\
\hline Male, No. (\%) & $102(58)$ & $100(58)$ & $99(54)$ & $103(64)$ \\
\hline \multicolumn{5}{|l|}{ Apgar score $\leq 5$, No. (\%) } \\
\hline 5 min after birth & $147(84)$ & $143(85)$ & $157(85)$ & $133(83)$ \\
\hline 10 min after birth & $102(66)$ & $109(71)$ & $111(70)$ & $100(67)$ \\
\hline Birth weight, mean (SD), g & $3300(530)$ & $3429(649)$ & $3297(610)$ & $3440(567)$ \\
\hline Gestational age, mean (SD), wk & $38.6(1.5)$ & $38.7(1.4)$ & $38.5(1.4)$ & $38.7(1.5)$ \\
\hline Length, mean (SD), cm & $50.6(2.9)$ & $50.8(3.1)$ & $50.5(2.9)$ & $50.9(3.1)$ \\
\hline Head circumference, mean (SD), cm & $34.0(1.9)$ & $34.3(1.7)$ & $34.0(1.6)$ & $34.2(2.0)$ \\
\hline Intubation in delivery room, №. (\%) & $135(77)$ & $136(80)$ & $146(79)$ & $125(78)$ \\
\hline Continued resuscitation at $10 \mathrm{~min}$, No. (\%) & $149(85)$ & $152(90)$ & $163(89)$ & $138(86)$ \\
\hline $\begin{array}{l}\text { Time to spontaneous respiration } \\
>10 \text { min, No. (\%) }\end{array}$ & $70(42)$ & $76(48)$ & $81(47)$ & $65(42)$ \\
\hline \multicolumn{5}{|l|}{ Cord blood } \\
\hline pH, mean (SD) & $6.9(0.2)$ & $6.9(0.2)$ & $6.9(0.2)$ & $7.0(0.2)$ \\
\hline Base deficit, mean (SD), mmol/L & $16.0(7.8)$ & $15.9(6.6)$ & $16.0(7.5)$ & $15.9(6.9)$ \\
\hline Seizures $^{c}$ & $46(26)$ & $56(33)$ & $57(31)$ & $45(28)$ \\
\hline Moderate encephalopathy ${ }^{d}$ & $135(77)$ & $128(75)$ & $146(79)$ & $117(72)$ \\
\hline Severe encephalopathy ${ }^{d}$ & $41(23)$ & $43(25)$ & $39(21)$ & $45(28)$ \\
\hline Inotropic support ${ }^{\mathrm{C}}$ & $42(24)$ & $33(19)$ & 35 (19) & $40(25)$ \\
\hline Anticonvulsants ${ }^{c}$ & $29(18)$ & $25(17)$ & 30 (19) & $24(17)$ \\
\hline $\begin{array}{l}\text { Abbreviation: IQR interquartile range. } \\
\text { a Percentages are based on the number of moth } \\
\text { were available. Because of rounding, not all pe } \\
\text { b Other race includes American Indian or Alaska } \\
\text { or other Pacific Islander, and more than } 1 \text { race. } \\
\text { c Data are from time of randomization. } \\
\text { d Encephalopathy was defined as the presence } \\
\text { signs in at least } 3 \text { of the following } 6 \text { categories } \\
\text { (moderate is lethargic, severe is stupor or com }\end{array}$ & $\begin{array}{l}\text { lates for whom data } \\
\text { um to } 100 . \\
\text { ian, Native Hawaiian } \\
\text { derate or severe } \\
\text { consciousness } \\
\text { taneous activity }\end{array}$ & \multicolumn{3}{|c|}{$\begin{array}{l}\text { (moderate is decreased activity, severe is no activity); (3) posture (moderate is } \\
\text { distal flexion or complete extension, severe is decerebrate); (4) tone } \\
\text { (moderate is hypotonia, severe is flaccid); (5) primitive reflexes (moderate is a } \\
\text { weak suck, severe is an absent suck, or moderate is incomplete Moro reflex } \\
\text { and severe is absent); and (6) autonomic nervous system-either pupil } \\
\text { (moderate is constricted; severe is deviated, dilated, or nonreactive to light), } \\
\text { heart rate (moderate is bradycardia, severe is variable heart rate), or } \\
\text { respiration (moderate is periodic breathing, severe is apnea). The number of } \\
\text { moderate or severe signs determined the extent of encephalopathy; if signs } \\
\text { were equally distributed, the designation was based on level of consciousness. }\end{array}$} \\
\hline
\end{tabular}

(95\% CrI, 0.91-1.93) for the group with $33.5^{\circ} \mathrm{C}$ for 120 hours, and 1.36 (95\% CrI, $0.81-2.21)$ for the group with $32.0^{\circ} \mathrm{C}$ for 120 hours. The posterior probabilities of increasing death with deeper cooling, longer cooling, or both compared with standard cooling (probability of RR $>1.0$ ) were $66 \%, 93 \%$, and $89 \%$, respectively.

\section{Discussion}

This trial demonstrated that neither longer nor deeper cooling reduced mortality or appeared neuroprotective in term neonates with moderate or severe hypoxic-ischemic encephalopathy. The rates of death or moderate or severe disability among infants randomized to the usual care group (cooling to $33.5^{\circ} \mathrm{C}$ for 72 hours) was $29 \%$; this is lower than the rate of $44 \%$ from the cooled group in the first NICHD Neonatal Research Network cooling trial ${ }^{1}$ and in other trials. ${ }^{2}$ This lower rate may reflect the lower rate of severe encephalopathy, lower acuity, and earlier initiation of cooling in this trial.
In this study, there was a higher mortality rate noted among infants who underwent cooling for 120 hours compared with 72 hours. The infants undergoing cooling for 120 hours at $32.0^{\circ} \mathrm{C}$ had the highest mortality rates but lowest disability rates. This finding needs to be interpreted with caution in view of the composite outcome, the early closure of the study, and the significant interaction between depth and duration of cooling. The Bayesian analyses indicated a 78\% probability that longer and deeper cooling reduces death or disability; however, this low disability rate (11\%) was offset by the increased mortality. Some earlier preclinical studies demonstrated that extending the duration or depth of cooling was neuroprotective ${ }^{5,6}$; other recent studies have not. ${ }^{11-13}$

The strengths of this study are that $71 \%$ of eligible infants were enrolled and primary outcome data were available for $95 \%$ of infants. Functional and cognitive outcome was evaluated by certified examiners unaware of treatment status. The limitations of this study are that the study was not powered to examine interactions and no adjustments were made for multiple comparisons. 


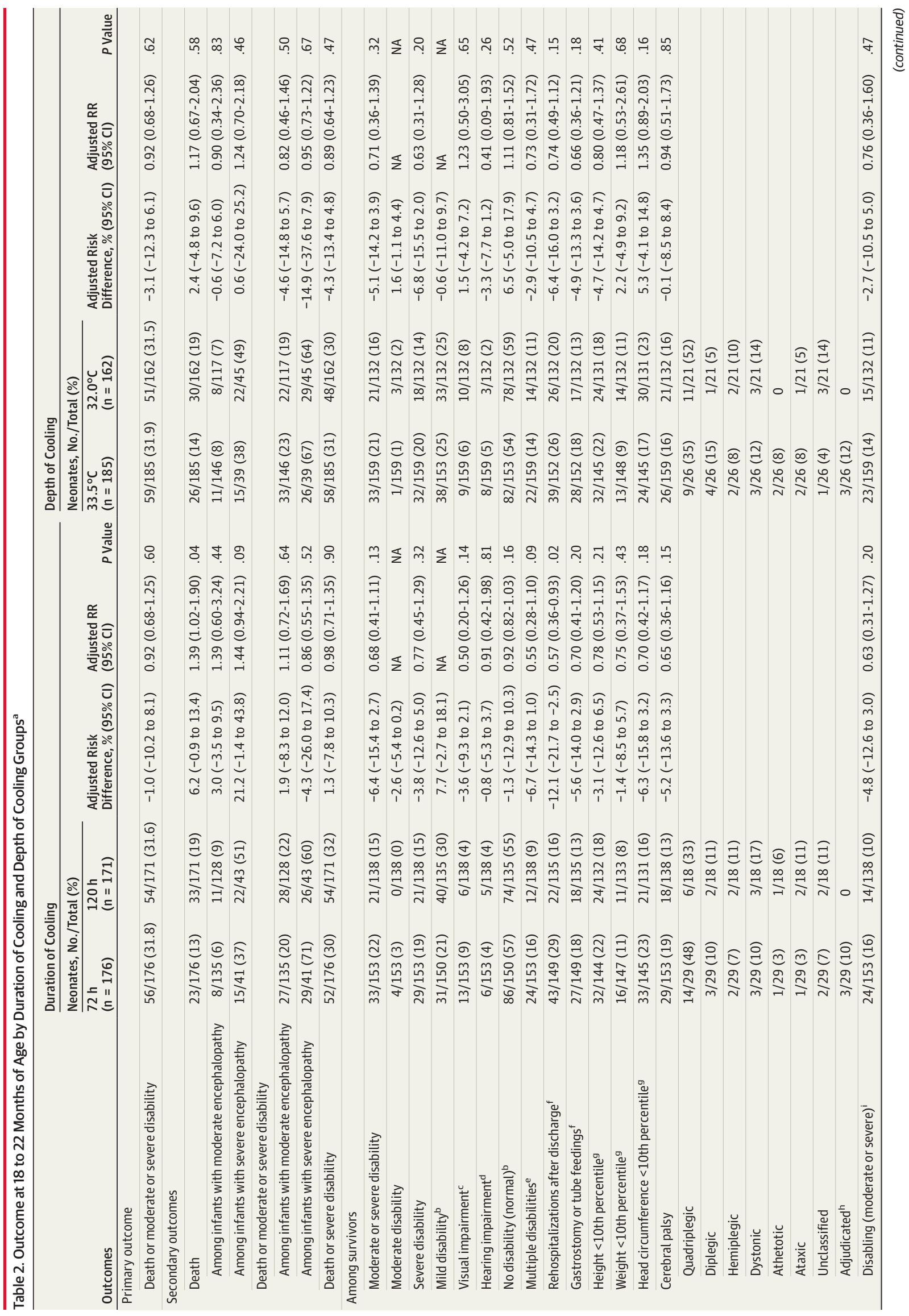




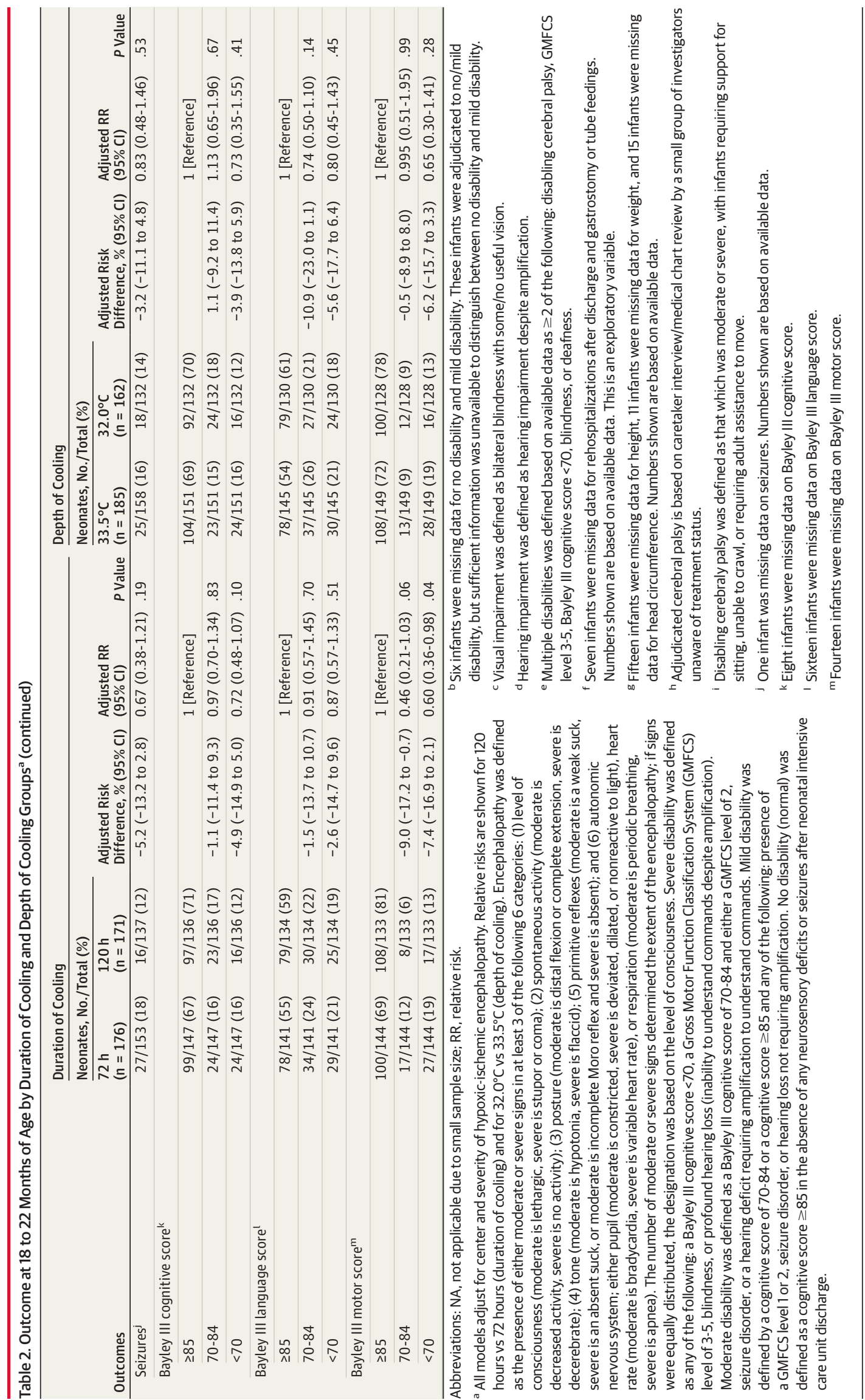




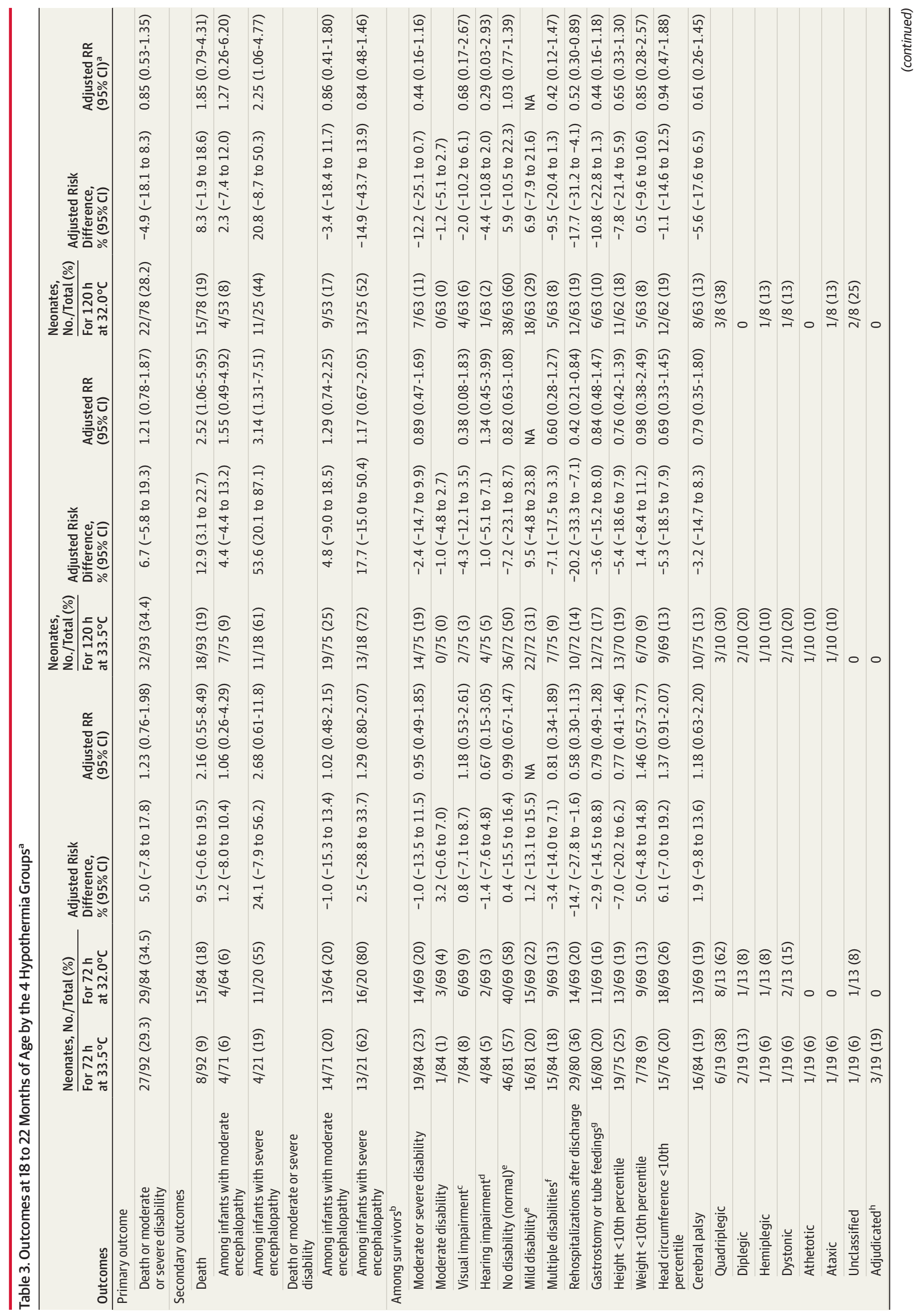




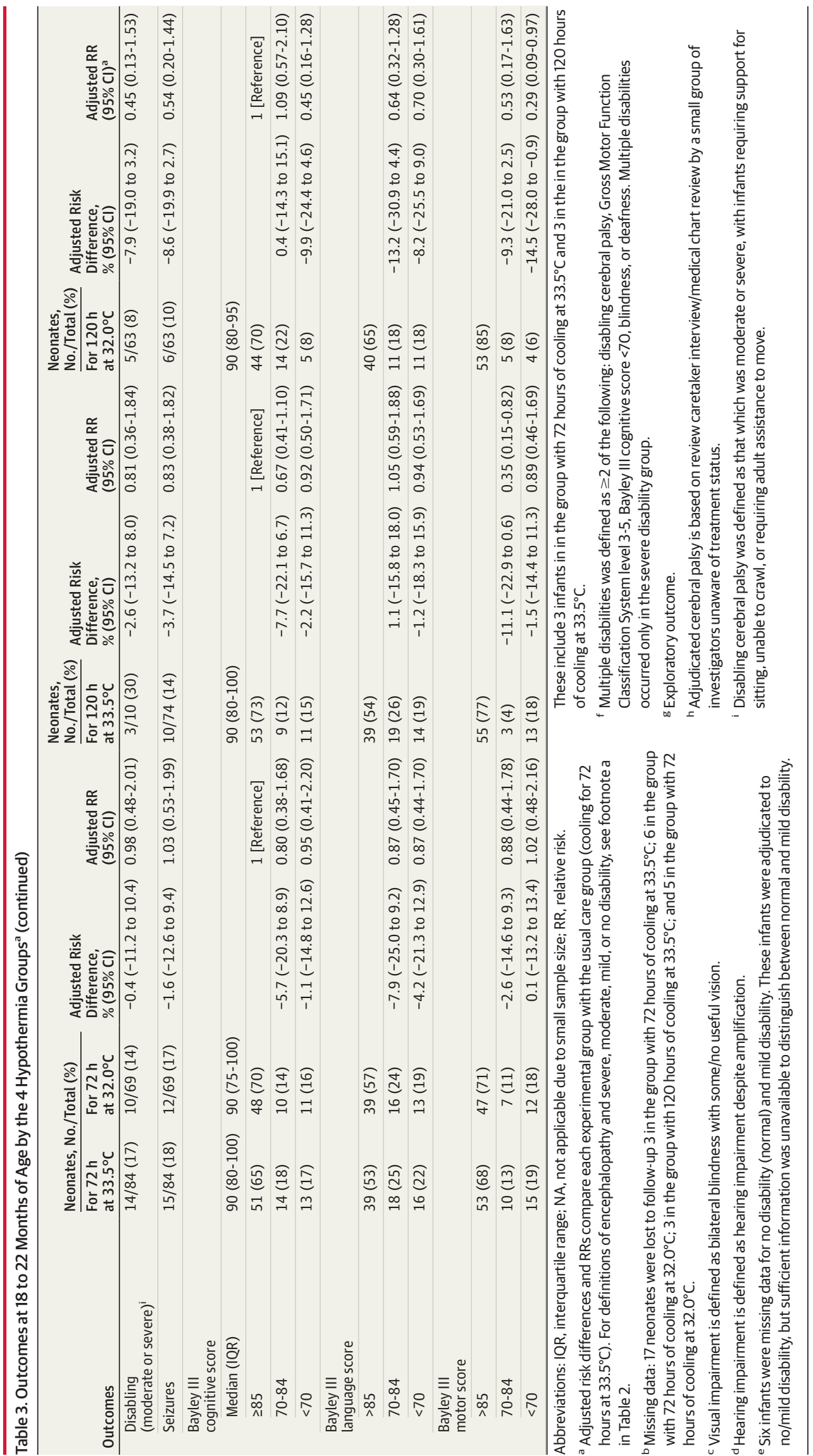




\section{Conclusions}

Among neonates of at least 36 weeks' gestational age with moderate or severe hypoxic-ischemic encephalopathy, cooling for longer than 72 hours, cooling to a depth lower than $33.5^{\circ} \mathrm{C}$, or both did not reduce death or disability at 18 months of age. However, the trial may be underpowered, and an interaction was found between longer and deeper cooling. These results support the current regimen of cooling for 72 hours at $33.5^{\circ} \mathrm{C}$.

\section{ARTICLE INFORMATION}

Accepted for Publication: May 30, 2017.

Author Affiliations: Department of Pediatrics, Wayne State University, Detroit, Michigan (Shankaran, Pappas, Bara); Department of Pediatrics, Women and Infants Hospital, Brown University, Providence, Rhode Island (Laptook); Social, Statistical and Environmental Sciences Unit, RTI International, Research Triangle Park, North Carolina (McDonald); Social, Statistical and Environmental Sciences Unit, RTI International, Rockville, Maryland (Das, Huitema); Department of Pediatrics, McGovern Medical School, the University of Texas Health Science Center at Houston (Tyson, Pedroza, Khan); Department of Pediatrics, Indiana University School of Medicine, Indianapolis (Poindexter, Harmon); Perinatal Institute, Cincinnati Children's Hospital Medical Center, Cincinnati, Ohio (Poindexter, Schibler, Grisby); Department of Pediatrics, University of lowa, lowa City (Bell, Brumbaugh); Department of Pediatrics, University of Texas Southwestern Medical Center, Dallas (Heyne, Chalak); Division of Neonatal and Developmental Medicine, Department of Pediatrics, Stanford University School of Medicine and Lucile Packard Children's Hospital, Palo Alto, California (Van Meurs); Department of Pediatrics, University of California, Los Angeles (Devaskar, Garg); Department of Pediatrics, Yale University School of Medicine, New Haven, Connecticut (Ehrenkranz); Department of Pediatrics, Perelman School of Medicine, University of Pennsylvania, the Children's Hospital of Philadelphia, Philadelphia, Pennsylvania (DeMauro); Department of Pediatrics, University at Buffalo, Buffalo, New York (Hartley-McAndrew); Department of Pediatrics, Rainbow Babies and Children's Hospital, Case Western Reserve University, Cleveland, Ohio (Walsh); Division of Neonatology, University of Alabama at Birmingham (Ambalavanan); University of New Mexico Health Sciences Center, Albuquerque (Watterberg); Department of Pediatrics, Nationwide Children's Hospital-The Ohio State University, Columbus (Shepherd); Department of Pediatrics, Emory University School of Medicine, Children's Healthcare of Atlanta, Atlanta, Georgia (Hamrick); Department of Pediatrics, University of Michigan, Ann Arbor (Barks); Department of Pediatrics, Duke University, Durham, North Carolina (Cotten); Department of Pediatrics, Children's Mercy Hospital and University of Missouri Kansas City School of Medicine, Kansas City (Kilbride); Eunice Kennedy Shriver National Institute of Child Health and Human Development, National Institutes of Health, Bethesda, Maryland (Higgins).

Author Contributions: Dr Das and Mr McDonald had full access to all of the data in the study and take responsibility for the integrity of the data and the accuracy of the data analysis.

Study concept and design: Laptook, Pappas, Das, Tyson, Poindexter, Schibler, Bell, Heyne, Devaskar, Ehrenkranz, Walsh, Cotten, Higgins.
Acquisition, analysis, or interpretation of data: Pappas, McDonald, Das, Tyson, Poindexter, Bell, Heyne, Pedroza, Van Meurs, Huitema, Grisby, Devaskar, Harmon, Chalak, DeMauro, Garg, Hartley-McAnderew, Khan, Ambalavanan, Brumbaugh, Watterberg, Shepherd, Hamrick، Barks, Cotten, Kilbride, Higgins.

Drafting of the manuscript: Tyson, Pedroza, Devaskar, Garg, Cotten.

Critical revision of the manuscript for important intellectual content: Laptook, Pappas, McDonald, Das, Tyson, Poindexter, Schibler, Bell, Heyne, Pedroza, Van Meurs, Huitema, Grisby, Devaskar, Ehrenkranz, Harmon, Chalak, DeMauro, Hartley-McAnderew, Khan, Walsh, Ambalavanan, Brumbaugh, Watterberg, Shepherd, Hamrick, Barks, Cotten, Kilbride, Higgins.

Statistical analysis: McDonald, Das, Pedroza. Obtained funding: Poindexter, Schibler, Bell, Walsh, Cotten.

Administrative, technical, or material support: Schibler, Huitema, Devaskar, Harmon, Chalak, Garg, Hartley-McAnderew, Khan, Shepherd, Hamrick, Higgins.

Study supervision: Das, Poindexter, Schibler, Devaskar, Barks, Cotten, Higgins.

Conflict of Interest Disclosures: All authors have completed and submitted the ICMJE Form for Disclosure of Potential Conflicts of Interest. Dr Cotten reports receipt of advisory board fees from GW Pharmaceuticals. No other disclosures were reported.

Funding/Support: The National Institutes of Health, the NICHD, and the National Center for Advancing Translational Sciences provided grant support for the Neonatal Research Network through cooperative agreements.

Role of the Funder/Sponsor: NICHD staff participated in the design and conduct of the study, interpretation of the data, review and approval of the manuscript, and decision to submit the manuscript for publication.

Group Information: The Eunice Kennedy Shriver National Institute of Child Health and Human Development Neonatal Research Network include: NRN steering committee chair: Richard A. Polin, MD, Division of Neonatology, College of Physicians and Surgeons, Columbia University (2011-present). Alpert Medical School of Brown University and Women and Infants Hospital of Rhode Island (U1O HD27904): Martin Keszler, MD; William Oh, MD Betty R. Vohr, MD; Angelita M. Hensman, MS, RNC-NIC; Robert T. Burke, MD, MPH; Melinda Caskey, MD; Nicholas Guerina, MD, PhD; Andrea M. Knoll; Emilee Little, RN, BSN; Ross Sommers, MD; Birju A. Shah, MD, MPH; Elisa Vieira, RN, BSN; Barbara Alksninis, RNC, PNP; Mary Lenore Keszler, MD; Elisabeth C. McGowan, MD. Case Western Reserve University, Rainbow Babies and Children's Hospital (U10 HD21364): Anna Marie Hibbs, MD; Nancy S. Newman, BA, RN; Bonnie S. Siner, RN; Eileen Stork, MD; Arlene Zadell, RN. Children's Mercy Hospital, University of Missouri Kansas City School of Medicine (U1O HD68284): William E.
Truog, MD; Eugenia K. Pallotto, MD, MSCE; Cheri Gauldin, RN, BSN, CCRC; Lisa Gaetano, MSN, RN; Anne M. Holmes, RN, MSN, MBA-HCM, CCRC; Kathy Johnson, RN, CCRC; Allison Knutson, BSN, RNC-NIC. Cincinnati Children's Hospital Medical Center, University of Cincinnati Medical Center, and Good Samaritan Hospital (U10 HD27853, UL1 TR77): Suhas G. Kallapur, MD; Barbara Alexander, RN; Lenora Jackson, CRC; Kristin Kirker, CRC; Teresa L. Gratton, PA; Stephanie Merhar, MD, MS; Greg Muthig, BA; Sandra Wuertz, RN, BSN, CLC; Kimberly Yolton, PhD. Duke University School of Medicine, University Hospital, University of North Carolina, and Duke Regional Hospital (U1O HD40492, UL1 TR1117): Ronald N. Goldberg, MD; Kimberley A. Fisher, PhD, FNP-BC, IBCLC; Joanne Finkle, RN, JD; Sandra Grimes, RN, BSN; Ricki F. Goldstein, MD; Patricia L. Ashley, MD, PhD; William F. Malcolm, MD; Kathryn E. Gustafson, PhD; Matthew M. Laughon, MD, MPH; Carl L. Bose, MD; Janice Bernhardt, MS, RN; Cindy Clark, RN; Diane D. Warner, MD, MPH; Janice Wereszcsak, CPNP; Sofia Aliaga, MD, MPH. Emory University, Children's Healthcare of Atlanta, Grady Memorial Hospital, and Emory University Hospital Midtown (U1O HD27851, UL1 TR454): Barbara J. Stoll, MD; David P. Carlton, MD; Ellen C. Hale, RN, BS, CCRC; Yvonne Loggins, RN; Colleen Mackie, BS, RT; Diane I. Bottcher, MSN, RN. Eunice Kennedy Shriver National Institute of Child Health and Human Development: Stephanie Wilson Archer, MA. Indiana University, Riley Hospital for Children and Methodist Hospital at Indiana University Health (U1O HD27856): Gregory M. Sokol, MD; Dianne E. Herron, RN, CCRC; Abbey C. Hines, PsyD; Susan Gunn, NNP-BC, CCRC; Lucy C. Smiley, CCRC. McGovern Medical School at the University of Texas Health Science Center at Houston, Children's Memorial Hermann Hospital: Kathleen A. Kennedy, MD, MPH; Julie Arldt-McAlister, MSN, APRN; Katrina Burson, RN, BSN; Allison G. Dempsey, PhD; Andrea F. Duncan, MD, MScr; Carmen Garcia, RN, BSN; Janice John, CPNP; Patrick M. Jones, MD; M. Layne Lillie, RN, BSN; Sara Martin, RN; Georgia E. McDavid, RN; Shawna Rodgers, RN, BSN; Saba Siddiki, MD; Daniel K. Sperry, RN; Patti L. Pierce Tate, RCP; Sharon L. Wright, MT (ASCP). Nationwide Children's Hospital and the Ohio State University Wexner Medical Center (U10 HD68278): Pablo J. Sánchez, MD; Leif D. Nelin, MD; Sudarshan R. Jadcherla, MD; Patricia Luzader, RN; Christine A. Fortney, PhD, RN; Nehal A. Parikh, MD; Bronte Clifford; Julie Gutentag, BSN; Marissa E. Jones, RN, MBA; Jodi A. Ulloa, MSN, APRN, NNP-BC; L. Yossef, MD; Erin Ferns; Tiffany Sharp; Jon Wispe, MD; Elizabeth Bonachea, MD; Jonathan Slaughter, MD, MPH; Louis G. Chicoine, MD; Brandon Hart, MD; Krista Haines, MD; Ish Gulati, MD; Michael Hokenson, MD; Roopali Bapat, MD; Nahla Zaghoul, MD; Ruth Seabrook, MD; Thomas Bartman, MD; Jennifer Fuller, MS, RNC; Sarah McGregor, BSN, RNC; Marliese Dion Nist, BSN; Tara Wolfe, BSN; Elizabeth Ann Rodgers, BSN. RTI International (U10 HD36790): Dennis Wallace, PhD; Marie G. Gantz, PhD; Jeanette O'Donnell Auman, BS; Margaret M. Crawford, BS, CCRP; 
Jenna Gabrio, BS, CCRP; Jamie E. Newman, PhD $\mathrm{MPH}$; James W. Pickett II, BS; Annie M. VonLehmden, BS; Kristin M. Zaterka-Baxter, RN, BSN. Stanford University and Lucile Packard Children's Hospital (U10 HD27880, UL1 TR93): David K. Stevenson, MD; M. Bethany Ball, BS, CCRC; Lynne C. Huffman, MD; Anne M. DeBattista, RN, PNP, PhD; Hali E. Weiss, MD; Maria Elena DeAnda, PhD; Casey E. Krueger, PhD; Melinda S. Proud, RCP. University of Alabama at Birmingham Health System and Children's Hospital of Alabama (U1O HD34216): Waldemar A. Carlo, MD; Monica V. Collins, RN, BSN, MaEd; Shirley S. Cosby, RN, BSN. University of California, Los Angeles, Mattel Children's Hospital, Santa Monica Hospital, Los Robles Hospital and Medical Center, and Olive View Medical Center (U10 HD68270): Teresa Chanlaw, MPH; Rachel Geller, RN, BSN. University of lowa and Mercy Medical Center (U10 HD53109, UL1 TR442): Tarah T. Colaizy, MD, MPH; Karen J. Johnson, RN, BSN; Diane L. Eastman, RN, CPNP, MA; Jacky R. Walker, RN; Claire A. Lindauer, RN; Jonathan M. Klein, MD; Jeffrey L. Segar, MD; John M. Dagle, MD, PhD; Julie B. Lindower, MD, MPH; Steven J. McElroy, MD; Glenda K. Rabe, MD; Robert D. Roghair, MD; Lauritz R. Meyer, MD; Cary R. Murphy, MD; Vipinchandra Bhavsar, MBBS; Dan L. Ellsbury, MD; Donia B. Campbell, RNC-NIC; Cary R. Murphy, MD; Vipinchandra Bhavsar, MBBS. University of New Mexico Health Sciences Center (U1O HD53089, UL1TR41): Robin K. Ohls, MD; Conra Backstrom Lacy, RN; Mary Ruffaner Hanson, RN, BSN; Sandra Sundquist Beauman, MSN, RNC; Carol H, Hartenberger, MPH, RN; Janell Fuller, MD; Andrea Freeman Duncan, MD, MScr; Jean R. Lowe PhD. University of Pennsylvania, Hospital of the University of Pennsylvania, Pennsylvania Hospital, and Children's Hospital of Philadelphia (U10 HD68244): Barbara Schmidt, MD, MSc; Haresh Kirpalani, MB, MSc; Kevin C. Dysart, MD; Soraya Abbasi, MD; Aasma S. Chaudhary, BS, RRT; Toni Mancini, RN, BSN, CCRC; Dara M. Cucinotta, RN; Judy C. Bernbaum, MD; Marsha Gerdes, PhD; Hallam Hurt, MD. University of Rochester Medical Center, Golisano Children's Hospital, and the University of Buffalo Women's and Children's Hospital of Buffalo (U1O HD68263, UL1 TR42): Carl D'Angio, MD; Ronnie Guillet, MD, PhD; Satyan Lakshminrusimha, MD; Nirupama Laroia, MD; Gary J. Myers, MD; Kelley Yost, PhD; Stephanie Guilford, BS; Rosemary Jensen; Karen Wynn, NNP, RN; Osman Farooq, MD; Anne Marie Reynolds, MD, MPH; Michael G. Sacilowski, MAT; Ann Marie Scorsone, MS; Holly I. M. Wadkins, MA; Ashley Williams, MSEd; Joan Merzbach, LMSW. University of Texas Southwestern Medical Center, Parkland
Health and Hospital System, and Children's Medical Center Dallas (U10 HD40689): Myra H. Wyckoff, MD; Luc P. Brion, MD; Lijun Chen, PhD, RN; Diana M. Vasil, MSN, BSN, RNC-NIC; Sally S. Adams, MS RN, CPNP; Catherine Twell Boatman, MS, CIMI; Alicia Guzman; Elizabeth T. Heyne, MS, MA, PA-C, PsyD; Lizette E. Lee, RN; Linda A. Madden, BSN, RN, CPNP; Emma Ramon, RNC-NIC, RN, BSN Wayne State University, University of Michigan, Hutzel Women's Hospital and Children's Hospital of Michigan (U1O HD21385): Beena G. Sood, MD, MS; Kirsten Childs, RN, BSN; Mary E. Johnson, RN, BSN Bogdan Panaitescu, MD; Sanjay Chawla, MD; Jeannette E. Prentice, MD; Lilia C. De Jesus, MD; Eunice Hinz Woldt, RN, MSN; Girija Natarajan, MD; Monika Bajaj, MD; John Barks, MD; Mary Christensen, RT; Stephanie A. Wiggins, MS. Yale University (U1O HD27871): Richard A. Ehrenkranz, MD. Data and safety monitoring committee: Christine A. Gleason, MD, chair, University of Washington; Marilee C. Allen, MD, Johns Hopkins University School of Medicine; Robert J. Boyle, MD, University of Virginia Health System; Traci Clemons, PhD, EMMES Corporation; Abhik Das, PhD (ex officio), RTI International; Martin Keszler, MD, Georgetown University Hospital; Menachem Miodovnik, MD, Washington Hospital Center; T. Michael O'Shea, MD, MPH, Wake Forest University School of Medicine; Michael G. Ross, MD, MPH, UCLA School of Medicine and Public Health; Steven J. Weiner, MS, the George Washington University; Marian Willinger, PhD (ex officio), Eunice Kennedy Shriver National Institute of Child Health and Human Development.

Disclaimer: The comments and views of the authors do not necessarily represent the views of the NICHD.

Additional Contributions: We are indebted to our medical and nursing colleagues and the infants and their parents who agreed to take part in this study.

\section{REFERENCES}

1. Shankaran S, Laptook AR, Ehrenkranz RA, et al; National Institute of Child Health and Human Development Neonatal Research Network. Whole-body hypothermia for neonates with hypoxic-ischemic encephalopathy. N Engl J Med. 2005;353(15):1574-1584.

2. Jacobs SE, Berg M, Hunt R, Tarnow-Mordi WO, Inder TE, Davis PG. Cooling for newborns with hypoxic ischaemic encephalopathy. Cochrane Database Syst Rev. 2013;1(1):CD003311.

3. Shankaran S, Pappas A, McDonald SA, et al; Eunice Kennedy Shriver NICHD Neonatal Research
Network. Childhood outcomes after hypothermia for neonatal encephalopathy. N Engl J Med. 2012; 366(22):2085-2092.

4. Azzopardi D, Strohm B, Marlow N, et al; TOBY Study Group. Effects of hypothermia for perinatal asphyxia on childhood outcomes. N Engl J Med. 2014;371(2):140-149.

5. Thoresen M, Bågenholm R, Løberg EM, Apricena F, Kjellmer I. Posthypoxic cooling of neonatal rats provides protection against brain injury. Arch Dis Child Fetal Neonatal Ed. 1996;74(1):F3-F9.

6. Bennet L, Roelfsema V, George S, Dean JM, Emerald BS, Gunn AJ. The effect of cerebral hypothermia on white and grey matter injury induced by severe hypoxia in preterm fetal sheep. J Physiol. 2007;578(Pt 2):491-506.

7. Shankaran S, Laptook AR, Pappas A, et al; Eunice Kennedy Shriver NICHD Neonatal Research Network. Effect of depth and duration of cooling on deaths in the NICU among neonates with hypoxic ischemic encephalopathy: a randomized clinical trial. JAMA. 2014;312(24):2629-2639.

8. Palisano R, Rosenbaum P, Walter S, Russell D, Wood E, Galuppi B. Development and reliability of a system to classify gross motor function in children with cerebral palsy. Dev Med Child Neurol. 1997; 39(4):214-223.

9. Bayley N. Manual for the Bayley Scales of Infant and Toddler Development. 3rd ed. San Antonio, TX: Hardcourt Assessment; 2006.

10. Pedroza C, Tyson JE, Das A, Laptook A, Bell EF, Shankaran S; Eunice Kennedy Shriver National Institute of Child Health and Human Development Neonatal Research Network. Advantages of Bayesian monitoring methods in deciding whether and when to stop a clinical trial: an example of a neonatal cooling trial. Trials. 2016;17(1):335.

11. Davidson JO, Yuill CA, Zhang FG, Wassink G, Bennet L, Gunn AJ. Extending the duration of hypothermia does not further improve white matter protection after ischemia in term-equivalent fetal sheep. Sci Rep. 2016;6:25178.

12. Alonso-Alconada D, Broad KD, Bainbridge $A$, et al. Brain cell death is reduced with cooling by $3.5^{\circ} \mathrm{C}$ to $5^{\circ} \mathrm{C}$ but increased with cooling by $8.5^{\circ} \mathrm{C}$ in a piglet asphyxia model. Stroke. 2015;46(1):275-278.

13. Wood T, Osredkar D, Puchades M, et al. Treatment temperature and insult severity influence the neuroprotective effects of therapeutic hypothermia. Sci Rep. 2016;6(6):23430. 